\title{
THE INFLUENCE OF PORES SIZE AND TYPE OF AGGREGATE ON CAPILLARY HEAT AND MASS TRANSFER IN POROUS
}

\author{
Nova Ismail ${ }^{\star}$, Sudjito Soeparman ${ }^{1}$, Denny Widhiyanuriyawan ${ }^{1}$, Widya Wijayanti ${ }^{1}$ \\ ${ }^{1}$ Department of Mechanical Engineering, Brawijaya University
}

One of the latest development of absorber plate in solar still application is the implementation of porous media. This study aims to analyze the effect of aggregate's pore size and type towards the capillary-driven flow and evaporation process in porous media. In order to enhance the evaporation process five different types of porous media had been chosen, namely concrete consisted river sand with the particle size of 0.125 and $0.250 \mathrm{~mm}$, ferrous sand concrete with particle size of 0.125 and $0.250 \mathrm{~mm}$, and natural stone as the comparison material. Top side of the specimens was exposed in a heater with 18.2 W, 27.3 W and 36.4 W. The bottom side of specimen was exposed in seawater which flowed capillary and evaporated. The value of thermal conductivity and porosity in porous media greatly affect the temperature distribution caused by the heat transfer process. Specimens with smaller particle size has a higher thermal conductivity which resulting in a larger heat transfer rate. Concrete with ferrous sand as aggregate has a better heat transfer rate than river sand specimen. The largest heat transfer rate obtained in concrete with $0.125 \mathrm{~mm}$ ferrous sand with the value of $0.256 \mathrm{~W}, 0.402 \mathrm{~W}$ and $0.524 \mathrm{~W}$ in every power addition. The rate of mass transfer value equals to the rate of evaporation that occurs and strongly depends on the capillary force of each specimen. The evaporation rate data is proportional to the heat transfer rate of each specimen. However the natural stone specimen has a higher evaporation rate than expected due to better interconnectivities between its channels.

\section{Key words: Porous media, Heat transfer, Evaporation rate, Seawater}

\section{INTRODUCTION}

\section{Background}

The phenomenon of heat and mass transfer is an interesting object of study to be developed. Many engineering applications are based on heat and mass transfer process. Various attempts has been examined to improve the efficiency of heat and mass transfer.

One of the innovation to improve the quality of heat and mass transfer is to use the porous media as the intermediary material. Porous media is a type of material that has interconnected channels (pores), whereas fluids can flow or occupies the empty spaces inside. Within its channels, the trapped fluids has a larger contact area. This larger contact area causes the larger rate of heat transfer between the porous material and fluids. Thus in this study the porous media were to be used as the basic material of a finned absorber plate in solar distillation.

The low productivity in solar still was generally caused by the low temperature of seawater [1]. An active and passive flat plate solar still was studied and resulting in $38 \%$ efficiency [2]. The usage of porous media as an absorber plate can cause sea water flowed within the empty channels. This make the seawater forms a thin layer, so that the process of heat transfer from solar energy to the fluids occurs more effectively. Along with the increasing efficiency of heat transfer process, the amount of seawater that could be evaporated also getting larger. Therefore, the solar still productivity also increases. Various types of porous media as an absorber plates have been studied [3]. The research aims to develop a capillary films based distillation system was analyzed using simulation models and experiments. The simulation model produces $1.3 \mathrm{~kg} / \mathrm{h} . \mathrm{m}^{2}$ at $11 \mathrm{am}-12 \mathrm{am}$. The result was highly efficient, by using a simple construction, this equipment can produce fresh water over $1 \mathrm{~m}^{3 /}$ day. Another study conducted by comparing the experimental results towards theoretical analysis of heat and mass transfer. The result is an increase of efficiency in accordance with the increase in solar radiation and the production of fresh water. The efficiency increased when the latent heat of condensation getting lower. The theoretical efficiency was about $60 \%$ at the maximum, while the experimental results had an efficiency of $50 \%$ [4]. An innovation of absorber plate by adding supplementary material to spread and create a thin layer of fluids, such as cotton, can increase the productivity of condensate water [5]. A study aims to find new absorber plate material with researching absorption, capillary rise, porosity, water repellence and heat transfer coefficient to select a suitable material for solar desalination applications has been held. Various materials are used andanalyzed, coral fleece with a porosity $(69.67 \%)$, absorbency (2 s), the capillary rise $(10 \mathrm{~mm} / \mathrm{h})$ and the heat transfer coefficient $\left(34.21 \mathrm{~W} / \mathrm{m}^{2}{ }^{\circ} \mathrm{C}\right)$ could improve the productivity of solar still better than wood pulp paper material, water coral fleece fabric and polystyrene sponge. This research was also used various models of the absorber plate such as flat absorber plate, stepped absorber plate and stepped absorber plate with wire mesh models. Maximum productivity was achieved at $4.28 \mathrm{~L} / \mathrm{d}$ using a stepped absorber plate with wire mesh models and the addition of water coral fleece material [6]. The fluid flow 
in porous media along with evaporation is often occurred in two-phase flow (liquid-vapor). Due to the two-phase flow and phase change phenomena, there are two type of areas on the porous medium namely the dry area and the saturated area [7]. By using porous media, the heat transfer process occurs in whole body of seawater. Unlike the conventional solar still which the heat transferred mostly only on the surface of seawater which caused a slower evaporation process [8],[9]. The usage of porous media as a fin in solar still application could enhanced the collector's efficiencies and the air temperature. The highest efficiency gained in solar still with the fin angle of 450 , while the least efficiency gained in solar still without fin [10].

Stone and concrete as an absorber plate material can be used as heat and mass transfer media simultaneously. Besides that, its simple production process and its abundant availability of raw materials was some beneficial factor for choosing both materials. Another advantage of stone and concrete material to be used as an absorber plate is that material is non-metallic. This minimizes the corrosion risk of the absorber plate which always in contact against seawater. Nevertheless the information on heat and mass transfer phenomena that occur in stone and concrete are still not widely studied in detail.

\section{Teoretical Review}

Upward liquid flow in porous media is dominated by capillary-driven flow. This phenomena only occur when intermolecular force between fluids and the channel's wall (adhesion) are greater than intermolecular force between fluids particles (cohesion) [11]. The capillary movement will stop at certain height when the capillary force reach the equality with the fluids weight force. This is the main mechanism when a porous media is only partially saturated and there were no energy given to the fluids [12]. Capillary force can be formulated as follows:

$p_{c}=\rho_{1}{ }^{*} g^{*} L_{h}=2^{*} \sigma^{*} \cos \theta / r_{\text {eff }}$

Where $p_{c}$ is the capillary force $(\mathrm{Pa}), \rho_{l}$ is the fluid density $\left(\mathrm{kg} / \mathrm{m}^{3}\right), \mathrm{g}$ is the gravity $\left(\mathrm{m} / \mathrm{s}^{2}\right), L_{h}$ is the maximum height of liquid fronts $(\mathrm{m}), \sigma$ is the surface tension of the fluid $(\mathrm{N} / \mathrm{m}), \theta$ is the contact angle of porous media (o) and $r_{\text {eff }}$ is the effective pore hole radius $(m)$. The amount of capillary force is proportional to the fluid surface tension and contact angle between the fluid and the walls of the channel. The larger the radius of a pore holes make the capillary force will be smaller.

The presence of heat flow from the upper side resulting in a decrease of the fluid's maximum capillary rise. The difin heat transfer process that occurs is divided into two. In the dry zone there are only porous media material, while in the wet zone there are two type of material which is the fluids and the porous media itself. Due liquid fluid has different conductivity values with porous media, the effective ferences of mixture condition between two zone resulted

thermal conductivity parameters used in the wet zone [13].

$k_{\text {eff }}=(1-\varepsilon) k_{p m}+\varepsilon k_{1}$

Where $k_{\text {eff }}$ is the effective thermal conductivity $[\mathrm{W} / \mathrm{m} \circ \mathrm{C}]$, $\mathrm{kpm}$ is the porous media thermal conductivity $[\mathrm{W} / \mathrm{m} \circ \mathrm{C}]$, $k_{\text {l }}$ is the fluids thermal conductivity $[\mathrm{W} / \mathrm{m} \circ \mathrm{C}]$ and $\varepsilon$ is the porosity of porous media [\%]. The decreasing maximum elevation continues until its reach the equilibrium condition.

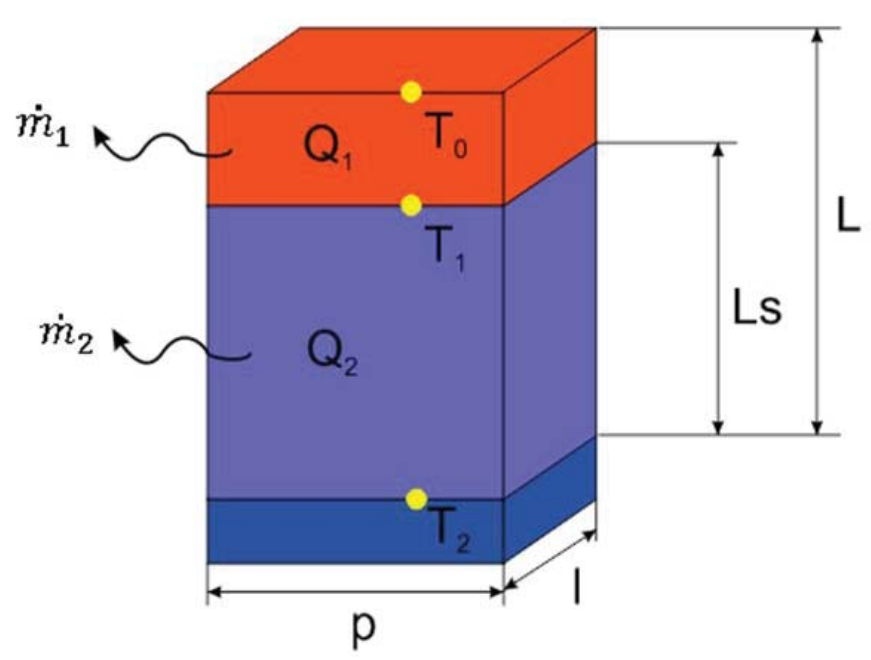

Figure 1: Heat and mass flow region in equilibrium condition

$Q_{1}=k_{p m}{ }^{*} A *\left(T_{0}-T_{1}\right) /\left(L-L_{s}\right)$

$Q_{2}=k_{\text {eff }} * A *\left(T_{1}-T_{2}\right) /\left(L-L_{s}\right)$

$Q_{\text {total }}=Q_{1}+Q_{2}$

Where $A$ is the cross sectional area $\left[\mathrm{m}^{2}\right], k_{\text {eff }}$ is the effective thermal conductivity $\left[\mathrm{W} / \mathrm{m}^{\circ} \mathrm{C}\right], T$ is the temperature at a certain point $\left[{ }^{\circ} \mathrm{C}\right], L$ is the height of porous media [m] and $L_{s}$ is the maximum of capillary rise [m] ,

As could be seen in Fig. 1, the total mass flow rate obtained from the accumulation of evaporation in the dry zone divided by the length of time reaching equilibrium condition and the mass flow rate of evaporation in the wet zone.

$$
\begin{aligned}
& \dot{m}_{\text {total }}=\dot{m}_{1}+\dot{m}_{2} \\
& \quad=\left\{\left[(L-L s)^{*} p^{*} l\right]^{*} \varepsilon^{*} \rho\right\} / s+Q_{2} /\left(h_{f g}+c_{p l}\left(T_{0}-T_{2}\right)\right) \\
& \quad=\left\{\left[(L-L s)^{*} p^{*} l\right]^{*} \varepsilon^{*} \rho\right\} / s+\left(k_{\text {eff }}{ }^{*} A^{*}\left(T_{0}-T_{2}\right) / L_{s}\right) /\left(h_{f g}+c p l\left(T_{0}-T_{2}\right)\right)
\end{aligned}
$$


Where $\rho$ is the density of the fluid $\left[\mathrm{kg} / \mathrm{m}^{3}\right], s$ is the time required to take the equilibrium condition $[s], h_{f g}$ is the latent heat of evaporation $[\mathrm{J} / \mathrm{kg}]$ and $c_{p l}$ is the specific heat capacity of the fluid $\left[\mathrm{W} / \mathrm{kg}{ }^{\circ} \mathrm{C}\right]$.

This study aimed to analyze the phenomena of evaporation that occurs in porous media. The study is based on the installation of finned absorber plate models. The seawater flows upward through the capillary channel of porous media. Conduction heat transfer occurs from the top move downwards the porous media where heat and mass transfer occur simultaneously.

\section{MATERIALS AND METHODS}

This research was conducted using experimental approach. A direct observation in phenomena that occurred was analyzed in order to get the conclusion. There were 5 types of porous media material to be tested. Before carrying out the experiments of evaporation rate in porous media, some pre-test is done to obtain details on the characteristics of the material. Some of these tests include thermal conductivity test, macro photograph and porosity testing. Macro photograph performed to determine the extent of the pores holes on the surface of the material. Macro photograph was held with 50x magnification and thereafter processed using image analysis software Image G. Thermal conductivity testing is done in Basic Mechanical Phenomenon laboratory of Mechanical Engineering department Brawijaya University. In order to obtain the chemical compound of each materials an XRF test was conducted. This test was conducted in Central Laboratory University of Malang which used the PANalytical/Minipal 4.Characteristics of porous media material will be taken into consideration during the process of analysis of experimental results.

There are four most dominant composition in River sand. Namely Fe (37\%), Ca (20\%), Si (25\%) and Al (10\%). Meanwhile as could be seen in Table 1, the most dominant composition of ferrous sand was $\mathrm{Fe}(83 \%)$. The Fe concentration of ferrous sand was the greatest among the three materials used in this study. In general, ferrous sand has a black color, specific weight of $1.8 \mathrm{ton} / \mathrm{m}^{3}$, particle size of $1 / 16-2 \mathrm{~mm}$ and has a high magnetic potential.In general the natural stone specimen has a similar composition with the river sand. The main differences in both materials was the natural stone had fewer Fe concentration than River sand. The natural stone had more variety in composition than River sand. Physically the cement material has a specific weight of $1.31 \mathrm{gr} / \mathrm{cm}^{3}$ which satisfy the requirement of SNI 0013-77. As could be seen in Fig. 6, the most dominant chemical compound of Portland cement was $\mathrm{Ca} 76 \%$.
Table 1: Chemical composition of each materials (units of percentage [\%])

\begin{tabular}{|c|c|c|c|c|}
\hline Composition & $\begin{array}{l}\text { River } \\
\text { sand }\end{array}$ & $\begin{array}{c}\text { Ferrous } \\
\text { sand }\end{array}$ & Cement & $\begin{array}{c}\text { Natural } \\
\text { stone }\end{array}$ \\
\hline $\mathrm{Al}$ & 9.5 & 3 & 1.8 & 9.3 \\
\hline $\mathrm{Si}$ & 24.6 & 3.4 & 6.83 & 27 \\
\hline $\mathrm{K}$ & 2.08 & 0.097 & 0.64 & 4.1 \\
\hline $\mathrm{Ca}$ & 19.8 & 1.1 & 75.79 & 19.1 \\
\hline $\mathrm{Ti}$ & 1.99 & 5.07 & 0.63 & 1.84 \\
\hline $\mathrm{V}$ & 0.12 & 0.69 & 0.03 & 0.108 \\
\hline $\mathrm{Cr}$ & 0.074 & 0.13 & 0.051 & 0.069 \\
\hline $\mathrm{Mn}$ & 0.72 & 0.39 & 0.16 & 0.7 \\
\hline $\mathrm{Fe}$ & 37.2 & 83.16 & 8.43 & 32.5 \\
\hline $\mathrm{Ni}$ & 1.79 & 1.1 & 0.987 & 1.99 \\
\hline $\mathrm{Cu}$ & 0.33 & 0.14 & 0.11 & 0.29 \\
\hline $\mathrm{Zn}$ & 0.07 & 0.08 & 0 & 0.08 \\
\hline $\mathrm{Sr}$ & 1.03 & 0 & 0.26 & 1.2 \\
\hline $\mathrm{Eu}$ & 0.3 & 0.57 & 0.08 & 0.3 \\
\hline $\mathrm{Re}$ & 0.39 & 0.2 & 0.25 & 0.4 \\
\hline $\mathrm{P}$ & 0 & 0.1 & 0 & 0.49 \\
\hline $\mathrm{Br}$ & 0 & 0.3 & 0 & 0 \\
\hline $\mathrm{Rb}$ & 0 & 0.43 & 0 & 0 \\
\hline $\mathrm{S}$ & 0 & 0 & 0.5 & 0 \\
\hline Mo & 0 & 0 & 1.3 & 0 \\
\hline In & 0 & 0 & 2.1 & 0 \\
\hline $\mathrm{Ba}$ & 0 & 0 & 0.2 & 0.55 \\
\hline
\end{tabular}

In this study the specifications of the seawater is as follows: $\mathrm{pH}$ value between 7:26 to 7:05, salinity between 10-20ppt, TSS ranged from 15-19 ppm, Na ranged between 3076.5 - $6153 \mathrm{mg} / \mathrm{I}$, Cl ranged between 5529-11058 mg / I, mg ranged between 370.5$741 \mathrm{mg} / \mathrm{I}$, SO4 ranged from $0.765-1.53 \mathrm{mg} / \mathrm{I}$. The composition of the salt from this seawater is as follow: $\mathrm{Na} 17.79 \pm 0.11 \%, \pm 1.17 \mathrm{Mg} \mathrm{0.01 \%}, \mathrm{Cl} 61.4 \pm 0.23 \%$, SO4 $0.7309 \pm 0.0013 \%$. [14].

Capillary-driven mass transfer test experiments conducted along with the addition of heat into the system. Some parameters observed in this study is the influence of porous media characteristic material to the temperature distribution in porous media, the amount of water that can be evaporated in the system, distribution of dry zones and wet zones[15]. 
Tabel 2: Material specification

\begin{tabular}{|c|c|c|c|c|}
\hline \multirow[t]{2}{*}{ Specimen } & \multirow[t]{2}{*}{ Specification } & Porosity & $\begin{array}{l}\text { Thermal } \\
\text { Conductivity }\end{array}$ & $\begin{array}{l}\text { Mean pores } \\
\text { hole radius }\end{array}$ \\
\hline & & $\%$ & $\mathrm{~W} / \mathrm{m}{ }^{\circ} \mathrm{C}$ & $\mathrm{mm}$ \\
\hline A & $\begin{array}{l}\text { Concrete with River sand aggregate } \\
\text { (particle size of } 0.125 \mathrm{~mm} \text { ) }\end{array}$ & 19.00 & 0.63 & 0.047 \\
\hline B & $\begin{array}{l}\text { Concrete with River sand aggregate } \\
\text { (particle size of } 0.250 \mathrm{~mm} \text { ) }\end{array}$ & 22.40 & 0.60 & 0.116 \\
\hline C & $\begin{array}{l}\text { Concrete with ferrous sand aggregate } \\
\text { (particle size of } 0.125 \mathrm{~mm} \text { ) }\end{array}$ & 17.80 & 0.72 & 0.121 \\
\hline D & $\begin{array}{l}\text { Concrete with ferrous sand aggregate } \\
\text { (particle size of } 0.125 \mathrm{~mm} \text { ) }\end{array}$ & 20.00 & 0.66 & 0.162 \\
\hline $\mathrm{E}$ & Natural stone & 14.60 & 0.46 & 0.189 \\
\hline
\end{tabular}

Some material has been selected for testing. There were five specimen types' namely natural stone and concrete with the ratio of 1 cement and 2 sand aggregate. The sand used was River sand with particle size of 0.125 $\mathrm{mm}$ and $0.250 \mathrm{~mm}$ and ferrous sand with particle size of $0.125 \mathrm{~mm}$ and $0.250 \mathrm{~mm}$. From the test results, obtained porous material characteristics data media. As it can be seen in Table 2.

\section{Data Retrieval}

The process of data collection was held based on the scheme as could be seen in Fig. 2(a). The depth of water inside the container was held at constant height about $1 \mathrm{~cm}$ from bottom side of specimen By using the measuring cup to be used as a reservoir, so the amount of seawater entering the container can be detected.

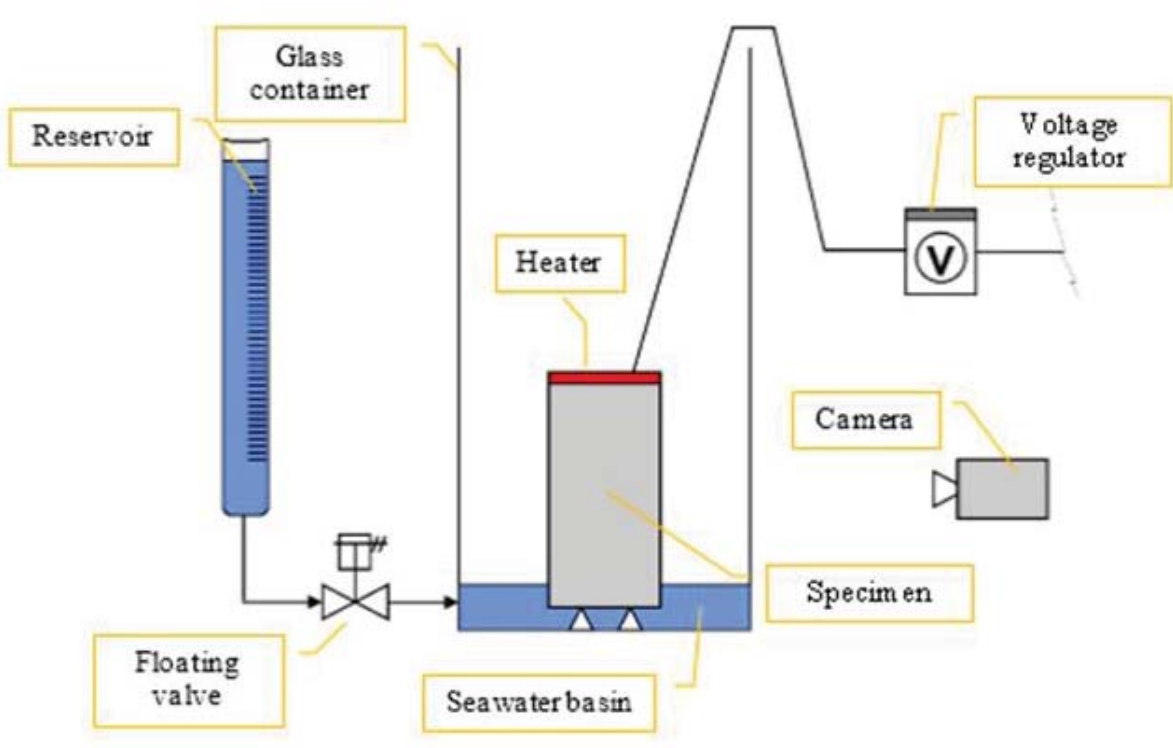

(a)

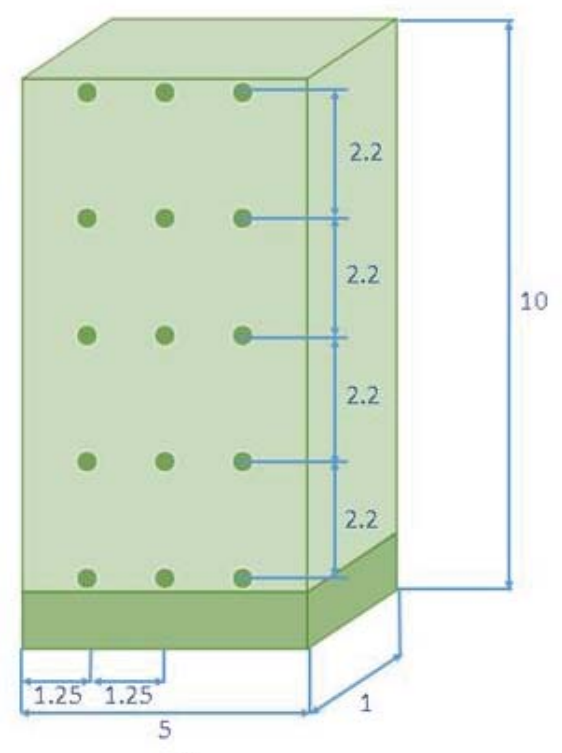

(b)

Figure 2: (a) Scheme of heat and capillary mass transfer apparatus; (b) Temperature distribution map

1. Filling the seeawater basin and callibration of floating valve in reservoir. This step is required in order to ensure the seawater level maintained constant, thus whenever the seawater in basin is decreased the floating valve will open and flew the seawater from reservoir
2. Placing the specimen in the basin and the installation of thermocouple. The heater sets in the upperside of specimen.

3. Starts the heating process and the power was controlled by the voltage regulator 
1. The data retrieval process starts. The image data taken by camera, while the temperature data taken in the data logger. The flowrate data taken by observing the decreasing seawater level in the reservoir

2. The data retrieval process taken for 2 hours.

3. The step 1-5 repeated for the other specimens and heating amount variations.

Data collection was performed for 2 hours. Some parameters that observed was volume decrease in the water reservoir, the surface temperature distribution of the specimen and the phenomenon of continuous drying obtained from the camera images. The data taken in every 5 minutes.

\section{Data Processing}

The temperature distribution data plotted using color plot. In order to achieve a more structured data, an interpolation has performed byusinglinear method.The images data from the camera can show the extent of dry and wet zones during the evaporation process. The height of each zone are calculated using image processing software. Due to the inequality of the maximum capillary rise, the height measured in 6 different locations. The average of height at 6 location used as the data of dry and wet zone calculation. This step was done with the assumption that porosity of porous media is homogeneously dispersed.The volume of water that can be occupied on each zone obtained by following equation:

$V_{d r y}=h_{d r y}{ }^{*} A{ }^{*} \varepsilon$

$V_{\text {wet }}=h_{\text {twet }}{ }^{*} A * \varepsilon$

With $V$ is the volume of water in each zone $\left(\mathrm{m}^{3}\right), h$ is the height of the zone $(\mathrm{m}), A$ is the cross-sectional area $\left(5 \times 1 \mathrm{~cm}^{2}\right)$ and $\varepsilon$ is the porosity of porous media. The total amount of evaporative water volume is the sum of the volume of water is reduced in a measuring cup with a volume of water in the dry zone.

\section{RESULTS AND DISCUSSION}

\section{The Temperature Distribution andthe Relationship of Mean Temperature Distribution with Thermal Conductivity}

Temperature distribution data on each specimen are described using a color plot. The data was taken after 2 hours of heating process. At this period, all of the specimens has reach its equilibrium state which there were no more decrease in wet zone. The results can be seen in Fig. 3.

Shownin Fig. 3that ineach addition of power, all these types of specimens has a wider temperature distribution range. Specimens $C$ have the highest peak temperature value (located in part which exposed to direct heat source) in overall power increase at that is $580^{\circ} \mathrm{C}, 790^{\circ} \mathrm{C}$ and $980^{\circ} \mathrm{C}$. Specimens $\mathrm{B}$ had the lowest peak temperature value on two variations of power addition in $18.2 \mathrm{~W}$ and $27.3 \mathrm{~W}$ namely $410^{\circ} \mathrm{C}$ and $610^{\circ} \mathrm{C}$ respectively. The specimen $\mathrm{E}$ has the lowest peak temperature value of $730^{\circ} \mathrm{C}$ on the addition of $36.4 \mathrm{~W}$.

Specimens $C$ had a higher temperature value when compared with the four other specimen types. The presence of ferrous sand which has a high conductivity is suppose to make the process of heat absorption in this material occurred better than River sand aggregate. High concentration of Fe which has a low Cp (449 J/kg K) makes the temperature increased rapidly at same value of given energy [15]. The concrete with River sand as aggregate and natural stone specimen, has a fairly high amount of $\mathrm{Si}$ and $\mathrm{Ca}$. Si and $\mathrm{Ca}$ has a higher $\mathrm{Cp}$ than $\mathrm{Fe}$, namely $710 \mathrm{~J} / \mathrm{kg} \mathrm{K}$ and $631 \mathrm{~J} / \mathrm{kg} \mathrm{K}$ respectively. Thus make these specimen has a lower temperature than concrete specimen with ferrous sand as aggregate.

Specimen $D$ has a value of temperatures lower than specimen $\mathrm{C}$ due to its higher porosity value. A higher porosity make the amount of seawater absorbed in porous media are also bigger. This resulted in the lower value of effective thermal conductivity in this specimen.

Fig. 4 shows the mean temperature distribution of each specimen. The dashed line represents the conductivity values of each specimen. In overall specimen, the mean temperature distribution is proportional to the thermal conductivity and also directly proportional to the amount of power addition.

The highest mean temperature distribution with the power of $18.2 \mathrm{~W}$ obtained by specimen $\mathrm{C}$ with a value of 43.400C. While the smallest mean temperature distribution value $33.720 \mathrm{C}$ owned by specimen $\mathrm{E}$. In power addition of $36.4 \mathrm{~W}$, specimens $\mathrm{C}$ had the largest mean temperature distribution that is $68.600 \mathrm{C}$, while specimens $B$ has the smallest value which is $55.890 \mathrm{C}$.

Specimens $C$ has the highest thermal conductivity values compared with the four other specimens. Despite having the same type of aggregate, the value of the thermal conductivity of the specimen $D$, has a lower value than specimen $\mathrm{C}$. This causes the value of temperature distribution in the overall power addition of specimen $D$ also smaller than specimen $\mathrm{C}$. The particle size used to affects the formation of the structure of concrete specimens. A larger particle size resulting in greater empty spaces area between the particles. Along with the greater particle size of aggregate, the heat transfer process that occurs could be further hampered. 

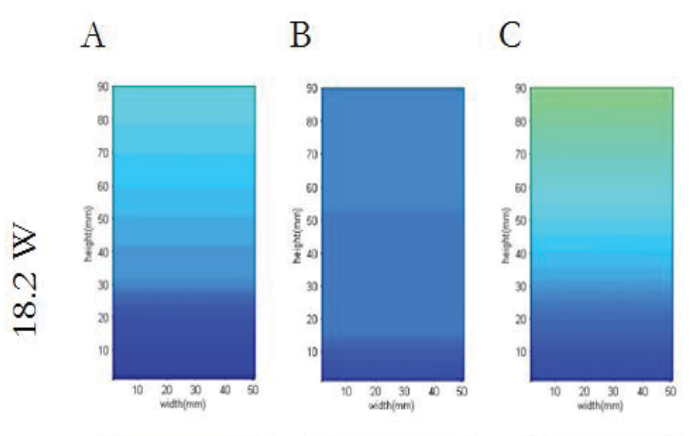

$\mathrm{D}$

E
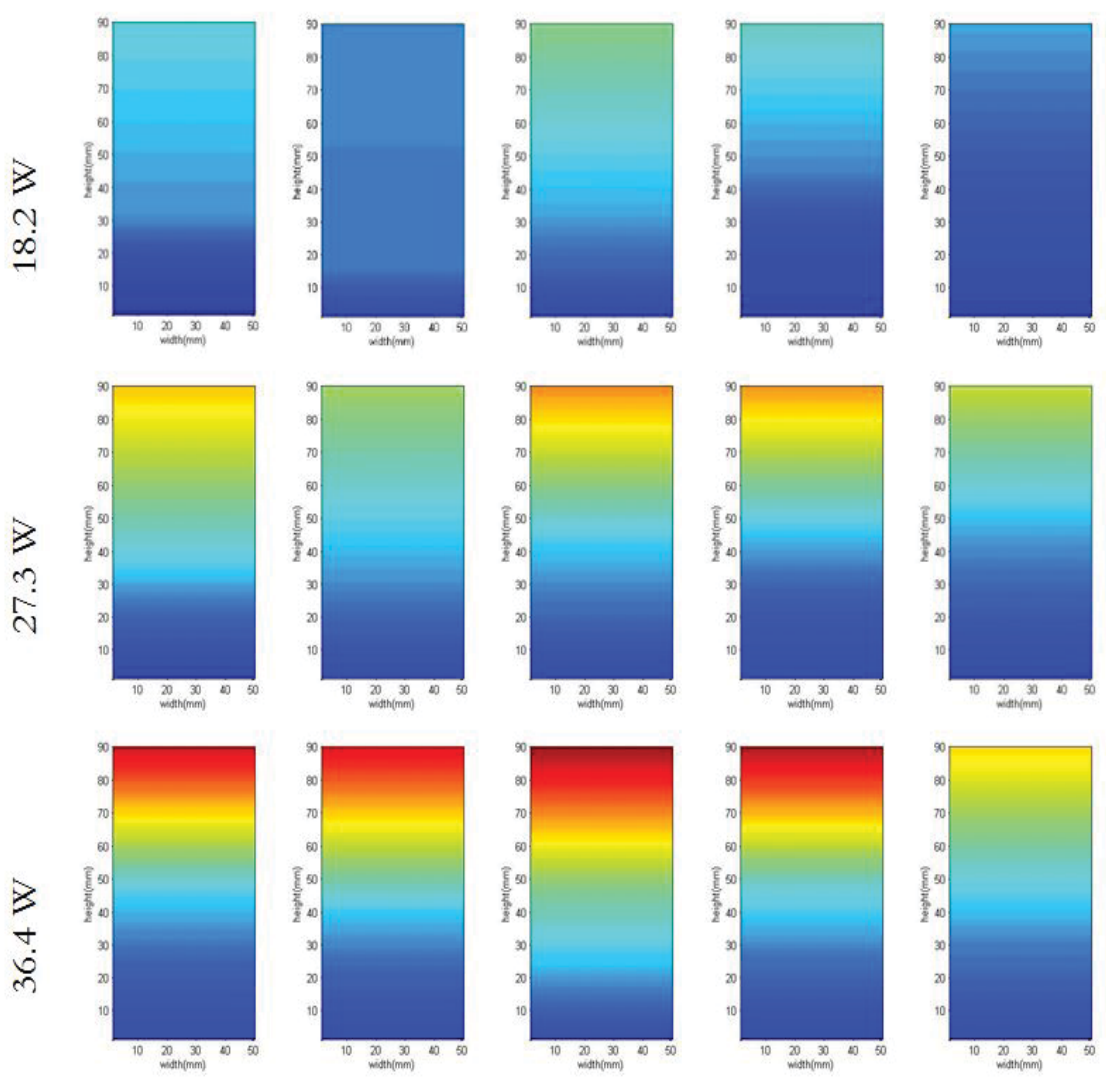

Temperature range $[\mathrm{C}]$

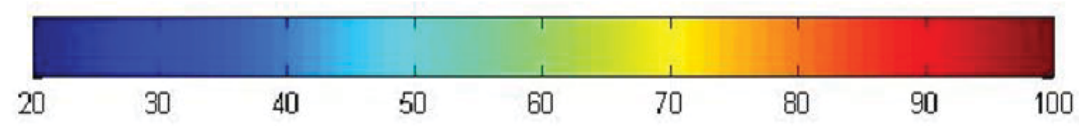

Figure 3:Temperature distribution of each specimen after 2 hours

\section{The Formation Of The Dry Zone And Wet Zone}

The height of capillary rise data processed by using equation (4). So the value of the empty spaces volume that can be occupied by the fluid at each zone could be determined. In order to make a better comparison between each specimen, a calculation based on the volume fraction has been performed. This is due to the different value of porosity in each specimen. Therefore, the value of the volume fraction obtained by the following equation

$f V_{d r y}=V_{d r y} /\left(V_{d r y}+V_{\text {wet }}\right)$

$f V_{\text {wet }}=V_{\text {wet }} /\left(V_{d r y}+V_{\text {wet }}\right)$

In Fig. 5, it can be seen that the highest volume fraction of the wetzone is owned by specimen B with a value of $85 \%$ on the addition of $18.2 \mathrm{~W}$ power. This is caused by the smaller amount of the specimen's temperature distribution.
So it can be seen that the dry zone (where the whole molecule of seawater in this zone has completely evaporated) is not quietly high.

In concrete material with the addition of ferrous sand as aggregate, the differences of volume fraction between each power addition is not too significant. This indicates that the dry zones where sea water has evaporated are greatly affected by the value of heat conduction from the heater.

From the entire data of volume fraction in wet and dry zones that occurred, it can be concluded that the capability of material in distributing the heat and fluids mass plays a significant role. Higher thermal conductivity of a material resulting in a less differences of decreased zone in each power addition.

\section{Heat Transfer Rate}

From the results of the temperature data retrieval at any point, the data processing performed by using Equation (2) and (3). So the value of the overall heat flow rate of each specimen were obtained as shown in Fig. 1 


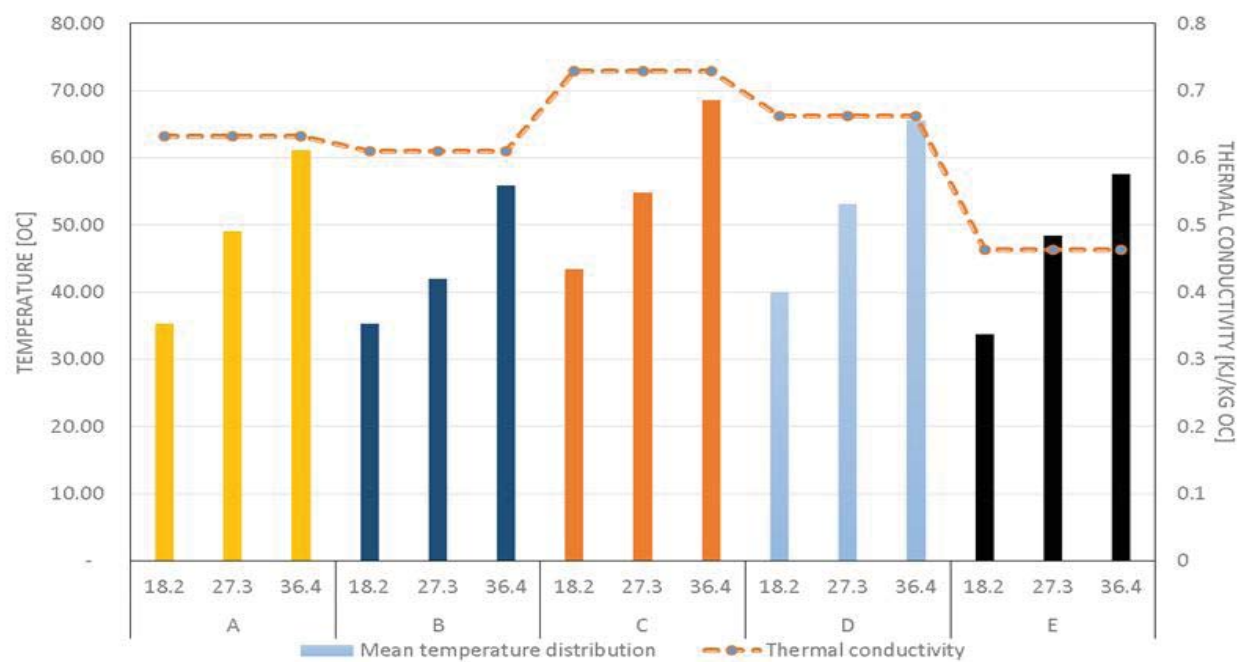

Figure 4: Mean temperature distribution of each specimen

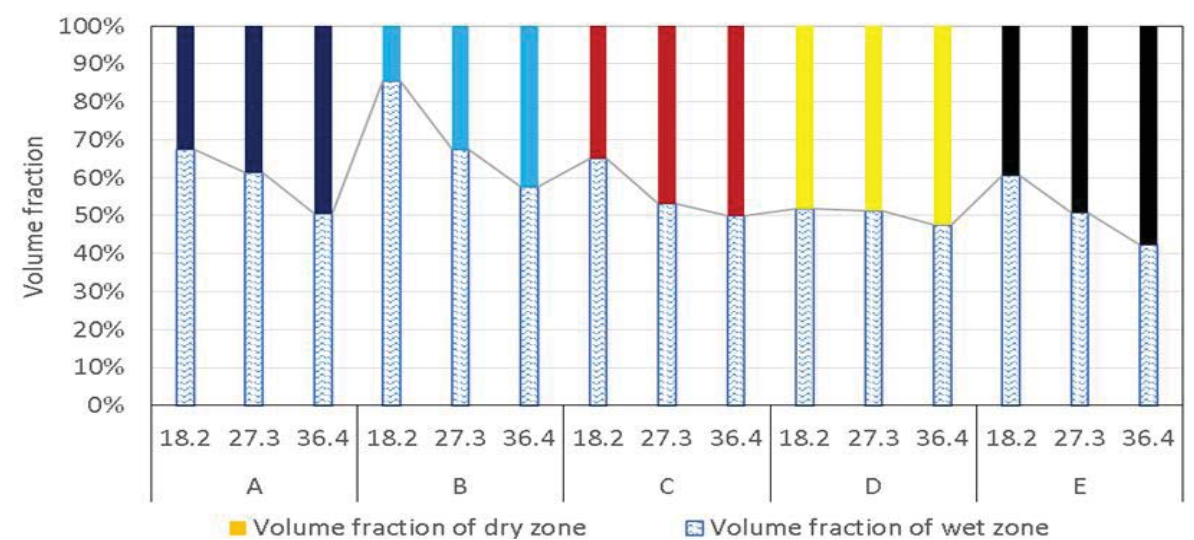

Figure 5: Volume fraction of each zone

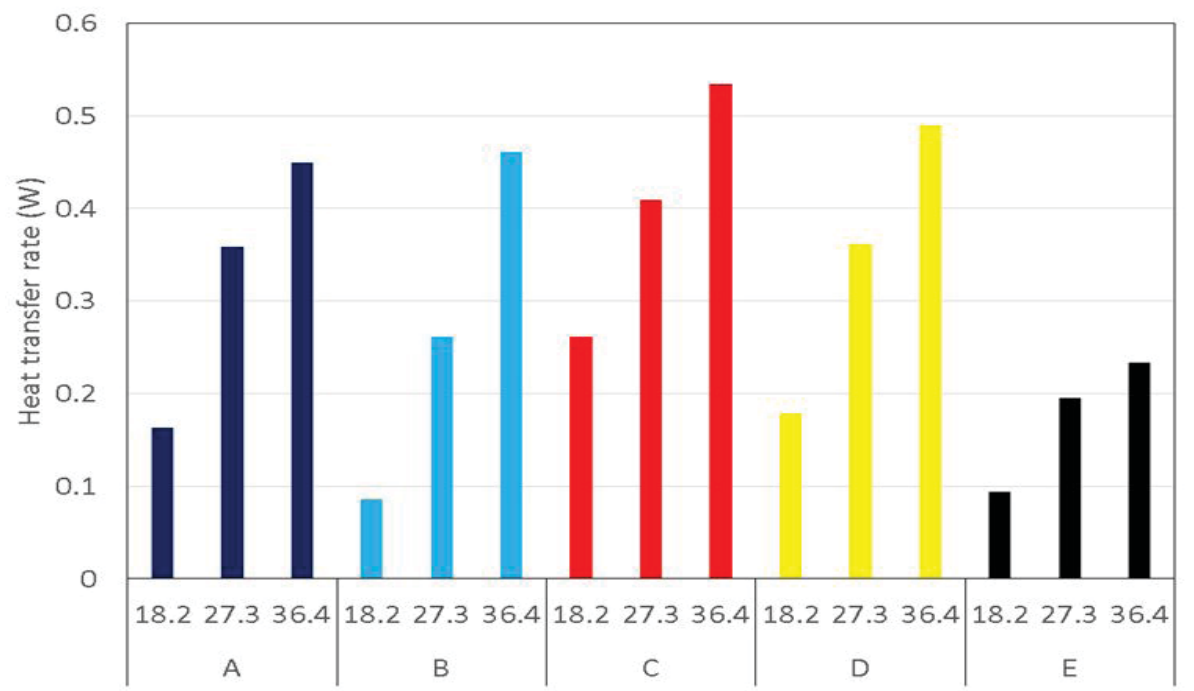

Figure 6: Total heat transfer rate in both zone of each specimen 


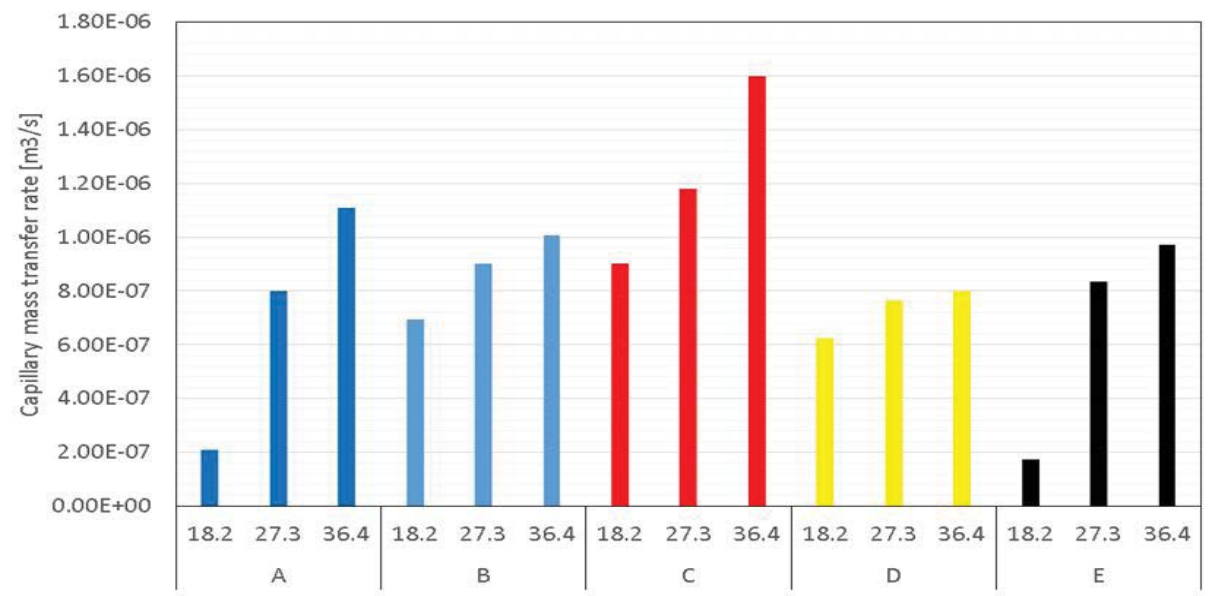

Figure 7: Capillary mass flow rate on each specimen data

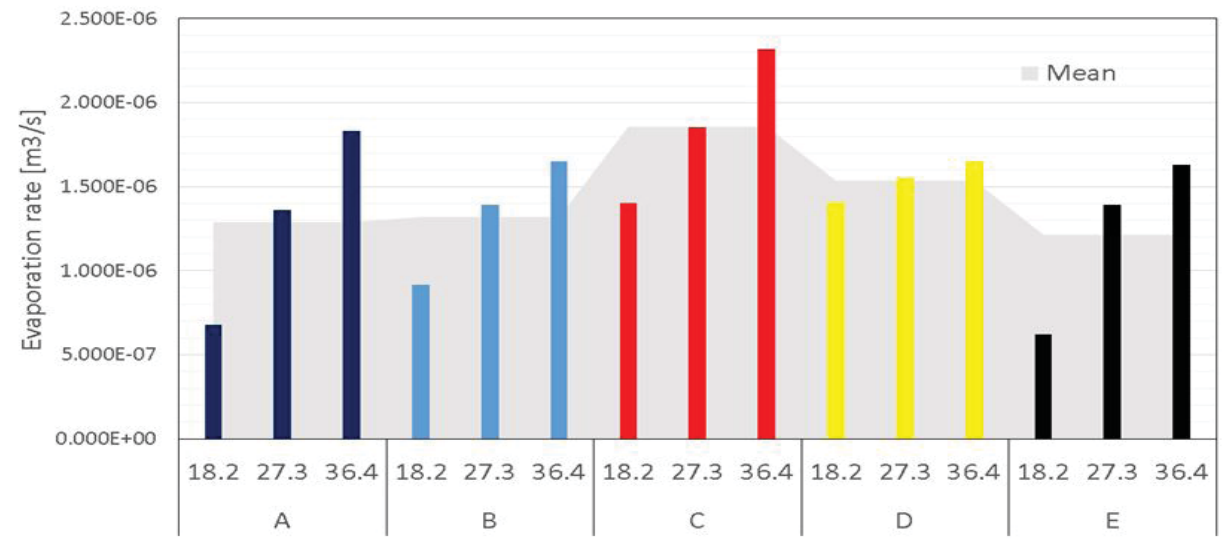

Figure 8: Evaporation rate of each specimen

In Fig. 6, the total value of the heat transfer rate on each specimen showed a trend similar to the mean temperature distribution data. The highest heat transfer rate gained in specimen $C$ with a value of $0.256 \mathrm{~W}, 0.402 \mathrm{~W}$ and $0.524 \mathrm{~W}$ in $18.2 \mathrm{~W}, 27.3 \mathrm{~W}$ and $36.4 \mathrm{~W}$ of applied electric power respectively.

Both concrete specimen showed that the total heat transfer rate was greater in smaller particle size specimens. However an irrelevancies occurred in specimen B with power addition of $36.4 \mathrm{~W}$. From the overall variation of applied power, specimen $E$ had the smallest average heat transfer rate.

With the use of the same type of fluid on the entire specimen, the value of thermal conductivity and porosity of the material have the most significant role in heat transfer that occurs. The greater the porosity of the material, the thermal conductivity value of the fluid becomes more dominant in the wet zone. This caused the effective thermal conductivity of the specimen becomes lower.

\section{Capillary Mass Flow Rate}

Capillary mass flow rate value obtained from the reduced water volume data in the reservoir. Fig. 10 shows that the mass flow rate value increased along with the addition of power. With the higher amount of heat, the evaporation occurred faster. The vaporized fluids in the closer zone to the heat source, leaves a vacant space which eventually filled by the fluid under due to its capillary movements. The mass flow rate of the specimen $\mathrm{C}$ has a value greater than the four other specimens. The high heat transfer rate in this specimen resulting in a faster fluids recirculation. Based on the porosity value the data showed an inverse trend whereas the higher porosity the mass flow rate should be also higher [16],[17].

However in this research found that due to the higher heat transfer takes place in specimen with low porosity, could force the replacement of fluids process inside the porous medium occurred faster. 
Specimens $E$ has a relatively high mass flow rat. Nevertheless the heat transfer rate from these specimens have less value compared to the four other specimens. It is predicted that the naturally formed interconnected channels resulting in a lower resistance to the capillary flow. Thus the capillary mass transfer in specimen $E$ has a relative high value than the other specimen.

\section{Evaporation Rate in Porous Media}

Figure 8 depicts the evaporation rate of each specimen. The amount of evaporation were identified on two parameters, namely the volume of water evaporated in the dry zone of porous media and the decreasing volume of seawater in the reservoir. During the study there are only a decresase in the wet zone, so it can be concluded that although there is a supply of seawater from the reservoir, the amount of capillary rise could not excess the evaporation process. Therefore the amount of evaporation rate is the accumulation of the decreasing seawater volume in the reservoir and the reduced volume of water in the dry zone in the interval of data retrieval.

Of the total specimens tested, specimen $\mathrm{C}$ on the provision of $36.4 \mathrm{~W}$ power has the highest evaporation rate which is $3: 1910-6 \mathrm{~m}^{3} / \mathrm{s}$. While at the power addition of $18.2 \mathrm{~W}$, the lowest evaporation rate gained in specimen $E$ with the amount of $1.1610-6 \mathrm{~m}^{3} / \mathrm{s}$.

On both the concrete material with the addition of ferrous sand showed an increase in the evaporation rate value along with the addition of power supplied. Despite this evaporation rate differences on every variation in each addition of power is not too great. This shows that in terms of the temperature distribution of material with the addition of ferrous sand has a good consistency. The mean evaporation rate of specimen $C$ is higher than specimen $D$ in every power addition. This is because the specimen $C$ has a higher thermal conductivity, and also the value of the porosity of this specimen is smaller than specimen D. Specimen $C$ has a relative high thermal conductivity and an adequate porosity for a better capillary evaporation process. In addition some parameters such as tortuosity on the material and the deposition of salt has a specific role that could affect the propagation flow of seawater propagation inside the porous media

The concrete material with River sand has a lower evaporation rate than the material with ferrous sand as aggregates. This is due to the lower thermal conductivity of concrete using River sand compared with the ferrous sand as aggregates. This indicates that the distribution of temperature inside the concrete material using River sand was worse than ferrous sand as aggregate. In terms of thermal conductivity specimen A has a higher value than specimen $B$ as shown in Table 1. Although specimen $B$ have a greater porosity that causes mass transfer of sea water in it better, the temperature distributed in this specimen was worse than specimen A. This caused the evaporation rate of this specimen are also lower.
Specimen $\mathrm{E}$ has the relative evaporation rate value. When compared with the other specimen, specimen $E$ has the lowest porosity and conductivity. However, these conditions do not make the amount of the evaporation rate on this specimen are also lowest. This is because the channel's interconnectivity inside this specimen were better than other specimen, due to its naturally formed specimen.

\section{CONCLUSIONS}

Generally specimens with small particle size has a higher thermal conductivity which resulting in a larger heat transfer rate values. In every particle size variation concrete with ferrous sand as aggregate has a better heat transfer rate than River sand. The largest heat transfer rate obtained in concrete with $0.125 \mathrm{~mm}$ ferrous sand aggregate with the value of $0.256 \mathrm{~W}, 0.402 \mathrm{~W}$ and 0.524 $\mathrm{W}$ in power addition of $18.2 \mathrm{~W}, 27.3 \mathrm{~W}$ and $36.4 \mathrm{~W}$ respectively.

The mass transfer rate values showed a trend similar to the rate of evaporation which strongly depended on the capillary force in each specimen. The evaporation rate data is proportional to the heat transfer rate of each specimen .Specimen C on the provision of $36.4 \mathrm{~W}$ power has the highest evaporation rate which is $3: 1910-6$ $\mathrm{m}^{3} / \mathrm{s}$. While at the power addition of $18.2 \mathrm{~W}$, the lowest evaporation rate gained in specimen $E$ with the amount of $1.1610-6 \mathrm{~m}^{3} / \mathrm{s}$. However natural stone specimen has a higher evaporation rate than expected due to better interconnectivities between its channels

\section{REFERENCES}

1. Siti N.S.; Omar El-Hadad; Syarifah b.A; Rahim; and Chew Few Ne. (2017)Solar still; unrevealed facts and reasons causing its low productivity.Journal of Engg. ResearchVol. 5 No. (1) pp. 181-19

2. Bilal, H.; Gahafoor, Abd.; and Munir, Anjum. (2016). Desalination of brackish water using dual acting solar still. Journal of Engg. ResearchVol. 4 No. (4) pp. 178-193

3. Bouchekima, B.; Gros, Bernard.; Ouahes, Ramdane.; and Diboun, Mostefa. (2001). Brackish water desalination with heat recovery.Desalination. vol.138. 47-155.

4. Bouchekima, B. (2002). A solar desalination plant for domestic water needs in arid areas of South Algeria. Desalination. vol. 153: 65-69.

5. Murugavel Kalidasa K.; Chockalingama Kn.K.S.K.; and Srithar K. (2008). An experimental study on single basin double slope simulation solar still with thin layer of water in the basin. Desalination 220: 687-693 . 
6. Hansen R.S.; Narayanan, C.S.; and Murugavel, K.K. (2015). Performance analysis on inclined solar still with different new wick materials and wire mesh. Desalination 358: 1-8

7. Beyhaghi; Saman; Geoffroy; Sandrine, Prat.; Marc.; Pillai.; Krishna M. (2014).Wicking and evaporation of liquids in porous wicks: a simple analytical approach to optimization of wick design. AIChE Journal, vol. 60 (n5): 1930-1940. ISSN 0001-1541

8. Tiwari, G.; and Yadav, Y. (1987). Comparative designs and long term performance of various designs of solar distiller. Energy conversion and management, 27(3):327-333.

9. Khalifa, A.-J.; Al-Jubouri, A.; and Abed, M. (1999). An experimental study on modified simple solar stills. Energy conversion and management, 40(17):18351847

10. Chabane, F., Moumm, N.i, Benramache, S., Bensahal, D., and Belahssen, O.. (2013). Collector efficiency by single pass of solar air heaters with and without using fins. Engineering Journal. Volume 17 Issue 3.

11. Cengel, A. Yunus.; and Cimbala, John M. (2006). Fluid mechanics: Fundamentals and aplication. McGraw Hill. New York
12. Hanžiča, L. and Ilic'a, R. (2003). Relationship between liquid sorptivity and capillarity in concrete. Cement and Concrete Research 33: 1385-1388

13. Nield D.A.; and A. Bejan. (2013). Convection in Porous Media, in Convection Heat Transfer. John Wiley \& Sons, Inc., Hoboken, NJ, USA

14. Anggara, Wahyu Tri. (2011).Studi Pemetaan Potensi Tambak Garam di Kecamatan Kabupaten Probolinggo Jawa Timur,Unpublished, Malang. Brawijaya University

15. Zhao T.S.; Liao Q. (1999). On capillary-driven flow and phase-change heat transfer in a porous structure heated by a finned surface: measurements and modeling. International Journal of Heat and Mass Transfer 43 (2000) 1141-1155

16. O.I. Popoola, J.A. Adegoke and O.O. Alabi, (2009). The Effects of Porosity and Angle of Inclination on the Deflection of Fluid Flow in Porous Media. Online Journal of Earth Sciences, 3: 14-22.

17. O.I. Popoola, J.A. Adegoke and O.O Alabi , (2007). A Laboratory Study of the Effects of Porosity on the Deviation from Darcy`s Law in Saturated Porous Media. Research Journal of Applied Sciences, 2: 892-899. 